\title{
Maintenance of growth in cystic fibrosis despite reduction in pancreatic enzyme supplementation
}

\author{
Jacqueline Lowdon, Mary C Goodchild, Henry C Ryley, Iolo J M Doull
}

\begin{abstract}
Twenty one children with cystic fibrosis were advised to decrease their pancreatic enzyme supplement (PES) dose to less than 10000 units lipase/kg/day. Mean PES dosage was significantly decreased in 15 patients from 18380 to 8647 units lipase/ kg/day. There were no significant changes in energy or fat intake, but there were significant increases in weight SD score, height SD score, and weight/height ratio. (Arch Dis Child 1998;78:377-378)
\end{abstract}

Keywords: pancreatic enzyme dosage; cystic fibrosis; growth

Case control studies in the $\mathrm{UK}^{1}$ and the USA ${ }^{2}$ have demonstrated a strong dose related association between pancreatic enzyme supplementation (PES) and the risk of developing fibrosing colonopathy. In 1995 the UK Committee on Safety of Medicines (CSM) recommended that the mean daily dose of PES should not exceed the equivalent of 10000 units of lipase/kg body weight/day irrespective of formulation. ${ }^{3}$

We advised children under our care with cystic fibrosis to reduce their dose of PES to within the recommendations, but were concerned that this might harm their nutritional status. Our hypothesis was that decreasing the dosage of PES might result in decreased nutrient intake, increased fat excretion, and resultant growth impairment. Therefore, we monitored prospectively the nutrition and growth of these children.

\section{Subjects and methods}

From October 1994 we reviewed the nature and dosage of PES for all patients under the care of the paediatric cystic fibrosis service at University Hospital of Wales. Following the 1995 CSM recommendations, all patients receiving more than 11000 units of lipase $/ \mathrm{kg}$ body weight/day were recommended to decrease their PES to less than 10000 units lipase $/ \mathrm{kg} /$ day. As most patients have some daily variation in PES intake, we excluded patients receiving between 10000 and 11000 units lipase/kg/day.

All patients were known to have fat malabsorption, which had improved with the addition of PES. The PES dose was decreased very slowly at each outpatient appointment under the guidance of the cystic fibrosis dietitian, with a subsequent telephone consultation to monitor progress. At each assessment the patients' height and weight were measured, and expressed as height SD score, weight SD score, and weight for height ratio. Before and after decreasing PES, three day food diaries using household measures (two week days and one weekend day) were recorded and coded. ${ }^{4}$ Mean energy intake was calculated using a computerised food composition database (Microdiet, University of Salford), and expressed as percentage daily energy derived from fat, fat intake $/ \mathrm{kg}$ body weight/day, total $\mathrm{kJ} / \mathrm{kg} /$ day, and energy intake as percentage of requirement.

Once the recommended dosage of PES was achieved, three day faecal fat excretion was recorded. All stools were collected between carmine markers into plastic buckets lined with polythene bags. The lipid content of the wet stool was measured, ${ }^{5}$ and expressed as mean daily fat excretion and coefficient of fat absorption. All patients were receiving greater than $3 \mathrm{~g}$ dietary fat/ $\mathrm{kg}$ body weight/ day at the time of collection. The upper limit of normal for faecal fat excretion in our laboratory is 5 g/day.

\section{Results}

With the exception of one patient, all received standard strength formulations of PES. Of 65 pancreatic insufficient patients under our care, 26 received PES greater than 10000 units lipase/kg/day. Five were receiving between 10000 and 11000 units lipase/kg/day, and were excluded. Of 21 patients receiving greater than 11000 units lipase/kg/day, 16 (12 male) decreased their lipase dosage to the required level, although one male subsequently required an ileostomy for an unrelated condition (initial dosage 14700 units lipase/kg/day). All faecal fat collections were successfully completed $(n=15)$ except in one female who refused (initial dosage 14286 units lipase/kg/day). Five patients were unable to decrease their dose of PES: three categorically refused, one required high strength PES, and one was awaiting a liver transplant. Although these patients were significantly older than those who reduced their PES (11.7 $v 5.1$ years, 95\% confidence interval (CI) $3.4,9.7 ; \mathrm{p}=0.001$ ), there was no significant difference in mean daily dose of PES (17 573 v 14797 units lipase/kg/day).

Table 1 shows PES dosage and anthropometric assessments. Mean follow up was for 1.4 years (range $0.7-2.5$ years). Over the same time there was a significant increase in weight SD score, height SD score, and weight/height ratio. Table 2 shows dietary analysis. There were no significant changes in percentage daily energy derived from fat, fat intake, daily energy intake, or energy intake expressed as percentage of requirement. 
Table 1 Mean (SD) lipase dosage and anthropometric assessment before and after reduction of lipase dosage ( $n=15)$

\begin{tabular}{llllll}
\hline & $\begin{array}{l}\text { At reduction in } \\
\text { PES dosage }\end{array}$ & $\begin{array}{l}\text { After reduction in } \\
\text { PES dosage }\end{array}$ & $\begin{array}{l}\text { Difference after } \\
\text { reduction }\end{array}$ & 95\% CI diff & $p$ Value \\
\hline Age (years) & $5.1(4.1)$ & $6.6(4.1)$ & $1.4(0.5)$ & & \\
PES intake unit lipase/kg/day & $18380(6280)$ & $8647(1187)$ & -9733 & 0.95 to 0.33 & $<0.001$ \\
Weight SD score & $-0.82(0.95)$ & $-0.18(0.79)$ & 0.64 & 0.64 & 1.00 to 0.28 \\
Height SD score & $-0.99(1.29)$ & $-0.35(1.07)$ & 5 & 8.5 to 0.7 & 0.023 \\
Weight/height ratio & $92(7.9)$ & $97(11.1)$ & 5 & \\
\hline
\end{tabular}

Table 2 Mean (SD) dietary analysis before and after reduction of lipase dosage $(n=15)$

\begin{tabular}{lllll}
\hline & $\begin{array}{l}\text { At reduction in PES } \\
\text { dosage }\end{array}$ & $\begin{array}{l}\text { After reduction in PES } \\
\text { dosage }\end{array}$ & 95\% CI diff & $p$ value \\
\hline \% Daily energy derived from fat & $38(3.5)$ & $39(6.4)$ & -4.8 to 3.5 & 0.6 \\
$\quad$ Range & $32-44$ & $23-46$ & -0.3 to 2.0 & 0.2 \\
Fat intake (g/kg body weight/day) & $5.8(1.9)$ & $4.9(1.2)$ & -17 to 184 & 0.1 \\
$\quad$ Range & $3.0-8.7$ & $3.0-7.4$ & 0.7 \\
Daily energy intake (kJ/kg/day) & $573(179)$ & $489(123)$ & -20.5 to 35.4 & \\
$\quad$ Range & $276-865$ & $326-752$ & & \\
Energy intake as \% of requirement & $137(29.1)$ & $145(32.1)$ & & \\
$\quad$ Range & $103-184$ & $76-209$ & \\
Faecal fat excretion (g fat/day) (n=14) & $\mathrm{NA}^{\star}$ & $4.1-15.4$ & & \\
$\quad$ Range & $\mathrm{NA}^{\star}$ & $91.9(2.0)$ & & \\
Coefficient of fat absorption (\%) $(\mathrm{n}=14)$ & & & & \\
$\quad$ Range & & &
\end{tabular}

$\star \mathrm{NA}=$ not available.

\section{Discussion}

We have shown, in 15 children with cystic fibrosis, that it is possible to decrease the dose of PES to less than 10000 units lipase/kg/day with acceptable fat absorption while maintaining nutritional intake.

We are unclear why the decrease in PES was associated with improved growth. Follow up was for at least a year in the majority of cases, and during that period patients were neither offered nor received increased nutrition. All had been diagnosed with cystic fibrosis at least one year before the reduction in PES, and only one child was pubertal. There were no significant changes in their management except that they received increased dietetic input. It is possible that very tight supervision of PES intake might have resulted in more appropriate usage.

The appropriate dose of PES is a balance between sufficient to prevent malabsorption and the increased risk of fibrosing colonopathy with some preparations when given at higher doses. More studies are required to define the maximal safe dosage for PES. Our findings suggest that the dose of PES can be reduced to those recommended in current guidelines in most patients without detriment to growth, and might even improve growth in the long term.

We would like to acknowledge the cooperation of the Biochemistry Laboratory at the University Hospital of Wales in analysing the faecal fat. With special thanks to Dr I McDowell and Mrs Heather Wheatley.

1 Smyth RL, Ashley D, O'Hea U, et al. Fibrosing colonopathy in cystic fibrosis: results of a case-control study. Lancet 1995;346:1247-51.

2 FitzSimmons SC, Burkhart GA, Borowitz D, et al. High dose pancreatic enzyme supplements and fibrosing colonopathy in children with cystic fibrosis. N Engl F Med 1997; 336: $1283-9$

3 Committee on the Safety of Medicines. Report of the Pancreatic Enzymes Working Party. London: Committee on the Safety of Medicines: Medicines Control Agency, 1995.

4 Paull AA, Southgate DAT, eds. McCance and Widowson's the composition of foods. London: HMSO, 1991.

5 van de Kamer JH, ten Bokkel Huinink H, Weyers HA. Rapid method for determination of fat in faeces. $\mathcal{F}$ Biol Chem 1949;177:347-55. 